\title{
Research on Countermeasures for Internet Financial Risk Management
}

\author{
Binjie Xu \\ School of Finance, Southwestern University of Finance and Economics, Chengdu 611130, China. \\ 1181612052@qq.com
}

Keywords: Internet finance, risk factors, risk management.

\begin{abstract}
In the paper, the risks of Internet finance including credit, regulation, liquidity, operations, market, technology, network security, and information asymmetry are teased out by reviewing the connotations and types of Internet finance. The corresponding risk management strategies are thereby proposed from the angle of government supervision, laws and regulations improvement, aiming to guide and protect consumers through the establishment of a credit supervision mechanism. The Internet finance atmosphere for mutual cooperation and supervision can be built through the training of professional talents and the establishment of an industry self-management system. A comprehensive Internet financial risk management and control system can be established through the implementation of internal assessment and other control measures.
\end{abstract}

\section{Introduction}

With the popularization of computers and mobile smart phones in the 21st century, the Internet has gradually entered the daily life of people. The penetration of the Internet has changed the business model of traditional finance. A rising financial model, Internet finance, was then born. The Internet finance as a universal financial model allows people to create much more wealth yet at a lower cost. Therefore a large number of people are lured to participate in the rising business model fueling the booming development of this emerging financial model. However, the risk factors behind this burgeoning industry marked by a fast rapid growth of should not be overlooked by people. There arises a higher risk accompanying the great convenience it has brought by. The reason can be explained that for one thing, the players are not quite familiar with its rules. For another, the regulators cannot seek any references for better management as there are no adequate laws and regulations combining with the nature of high risk that the Internet enjoys as it is an open platform. All these facts will cause irretrievable damages for many participants once in the event of a risk in such an extremely massive industry. As a result, the risk management in the field has received great attention from all parties. By mainly focusing on the domestic research results, this paper teases out and summarizes the risk type of Internet finance and the definition of Internet finance of the existing studies and provides a more comprehensive risk management and control countermeasures.

\section{A Summary of the Connotation and Types of Internet Finance}

In the section, the connotation of Internet finance is firstly introduced. And then some more general financial models are specialized on.

\subsection{Connotation of Internet Finance.}

Many scholars have given detailed and perfect definitions on the connotation of Internet finance.

$\mathrm{Xu}$ Ke (2015) believes that Internet finance is an emerging financial model which is based on many Internet tools such as payments, cloud computing, social networking, and search engines with the aim of conducting better financing, financial management, and information intermediary services. It is a newly financial service featuring stronger transparency, higher participation, better collaboration, lower intermediate costs, and more operationally convenient derived on the traditional financial services with the help of financial players who have combined the essence of Internet embodied by openness, equality, collaboration, and sharing with the new financial model [1]. Yang Xiaowei et al. (2016) mentioned that Internet finance is a new type of financial business. The 
traditional financial institutions and Internet companies of the Internet finance have taken great advantage of Internet technology and information and communication technologies in ways to realize financing, payment, investment, and information intermediary services [2]. Fu Zhangyan (2016) mentioned that Internet finance combines the essence of Internet that is openness, equality, competitiveness, free choice, and decentralization with the finance by utilizing the Internet technology. Thereby it has changed the traditional financial models in ways that the service processes have been simplified, the transaction costs have been lowered and barriers have been removed. It has made the professional financial information more accessible to ordinary investors and small, medium and micro enterprises [3]. Yang Guicang (2015) points out that what distinguishes the Internet finance from the traditional finance lies not only in the different media adopted in the respective development of their financial businesses, but also in the fact that participants in the Internet finance can profoundly understand the essence of Internet cooperation and development. In the context of Internet finance, the information of traditional financial business becomes more transparent, players participate in more services, greater flexibility in the cooperation between financial entities and financial intermediaries can be achieved, intermediate costs are lowered, and the application of financial instruments is facilitated [4]. Shen Li and Lin Dongdong (2014) point out that there is a more flexible definition that expresses the Internet finance as a traditional financial institution expanding practice to the Internet based on the traditional business or as a practice of a traditional non-financial institution extending its own business to the financial industry after the traditional non-financial institution gained some resources, which can be exemplified by Alibaba's Yu'E Bao (a financial product platform) [5].

To sum up, the Internet finance is a new financial model emerging from the combination of traditional finance and the Internet technology. Its essence is still traditional finance. However, compared to the traditional finance, the Internet finance enjoys one more abundant type of derivatives. Its operation is more convenient with lower transaction costs consequently attracting more ordinary investors and small and micro enterprises to be part of it.

\subsection{Overview of Types of Internet Finance.}

The advantages of Internet finance have prompted many investors to join into it though it is still a new industry, thus driving the rocket development and constant improvement of this emerging industry. So far, the Internet financial models that exist in the market mainly include:

\subsubsection{Third-Party Online Payment.}

The third-party online payment mainly innovates how to pay. Now, the dominant platforms for the third-party online payment are Yu'E Bao and Wechat.

The third party online payment adds the third party to the transaction process between the traditional buyer and the seller. In the transaction process, the buyer first pays the payment to the third party, and then informs the seller to deliver the goods. After the seller issues the goods, the buyer make confirmation and then pays the goods to the seller. The dominant third-party online payments are now Alipay and WeChat payment. The emergence of third-party online payment has helped to reduce the possible risk of fraud by the sellers in the traditional trading model, but at the same time, it may create operational risk and the risk of information asymmetry due to the incompleteness of network technology and loopholes.

\subsubsection{Non-Banking Investment and Financing.}

Non-banking investment and financing is an innovation in investment and financing methods. Its main types include P2P and crowd-funding.

The full name of the P2P model is Peer to Peer, which usually refers to personal to personal financing. Under the P2P model, commercial banks only serve as a channel for capital flow and no longer play the role of an intermediary. It means that the finance is conducted directly from individuals to individuals through an online financial platform. The model like this has effective delivered a result the lowered cost of financing. But for all this, potentially high credit risks and hidden dangers of cyber security are piling up on the P2P online loan platform. The reason behind it is the lack of a unified supervision system and perfect investigation for credit information. And the less 
transparency in capital flow information, short of well-defined regulations in business operations and unsecured and guaranteed loan mechanisms can be also blamed.

Crowd-funding mainly refers to the financial model that individuals or small and micro enterprises who are equipped with the competence of research and development show their innovative or emerging projects to the capital market in order to attracting the idle funds from the public. It mainly achieves the allocation of fund through the platform of Internet. The crowd-funding model boasts a dual monitoring mode of online application and offline supervision. Detailed speaking, after the borrower files online application, the platform operator then conducts credit investigation and project review of the borrower through the local agent. The information then is passed back to the platform to match with investor whose funds are issued in the forms of loan. However, it is prone to see moral hazards and information asymmetry risks in that the money raised by the model of crowd-funding is handed over to the agent for handling.

\subsubsection{Internet Financial Portal.}

Internet financial portals, being the innovation for Internet portals, at present mainly include the third-party consulting platform, and the online financial supermarket.

Apart from all these new typical models of Internet finance, the traditional financial industry has also delivered some businesses over Internet following the prevailing trend of the Internet, as demonstrated by the online banking and the mobile banking launched by some traditional commercial banks.

\section{Risk Factors of Internet Finance}

While all kinds of derivatives financial institutions derived from Internet finance have brought great convenience to investors, the potential risk factors of the Internet finance cannot be ignored. The industries of finance and Internet boast the nature of highly risky so that their combination has made the Internet finance bear the hallmark of multiple risks. The large great number of market players, information being more hidden, short and transit transaction flow, fast and frequent transaction have all added much more complexities to the risk of Internet finance which is something that is distinct from the traditional finance.

Domestic literature tells that there are the major following seven risk factors in Internet finance:

\subsection{Credit Risk.}

Credit risk of Internet finance is mainly reflected in both two aspects the financial institution and the customer. The traditional financial institution after being certified by authoritative bodies can thereby increase the trust for its institution by ways of the effective supervision. There is a fact that it is possible that all kinds of information on the Internet are false and is impossible to be verified on account of the virtual nature of the Internet, which can be seen as a major credit risk of Internet financial institutions for customers. What is more, as for the financial institution, many customers often create some false information when they made the application for financial services with the aim of winning the institution's confidence. But as the financial institution have no ways to verify that whether the information is authentic or not and whether the customer enjoys a good credibility or not, therefore, it is urgently essential for those financial institutions to find a way to get the true credibility of customers[11].

\subsection{Regulatory Risk.}

The regulatory risk of Internet finance is mainly the result of poor supervision of the regulatory bodies and the existence of many regulatory vacuums at the current stage. So far, there is a widespread phenomenon that the main supervision body of Internet financial is not clearly defined, which has given rise to the unclear business segmentation in many Internet financial institutions without relevant laws and regulations to abide by. On top of that, there is no explicitly regulation concerning about the market access and other regulations for online financial institutions, nor are there right definitions of the business model and the business attribute of those online financial institutions in laws and regulations that have already been introduced [6]. 


\subsection{Liquidity Risk.}

The development of the Internet technology and financial engineering has witnessed the constant innovation in financial products and services. Internet financial companies have adopted a large number of data models and econometric models in their operations and management exacerbating the market's liquidity leading to the shortage of funds. Take Yu'E Bao as an example to explain that. Yu'E Bao, as an open-end fund with a strong liquidity, enjoys the biggest selling point of being able to purchase and redeem at any time. But during the arrival period, large redemptions are bound to bring hit to liquidity, thus creating liquidity risk [7].

\subsection{Operational Risk.}

The Basel Committee on Banking Supervision defines the operational risk of Internet finance as the risk of loss, due to incomplete or ineffective situation in internal processes, personnel and systems and the loss cause by external events. As products financial business are becoming more diversified and more complex coupled with the growing trend of globalization and integration of financial markets, there are a growing number of operational risks leading to the increasingly more serious losses, showing that the operational risk has become an unavoidable topic[8].

\subsection{Market Risk.}

After many years of rapid development and constant improvement, the traditional industries have gained a relative rich experience in evading market risks. Thus they develop a relatively complete industry standard and system. While the Internet finance as an emerging industry with an extreme rapid growth stands far less appealing in financing compared to the traditional financing model under the same conditions. The reason behind that is due to the hidden nature and high uncertainty of the Internet. As a result, the Internet finance companies often set an extreme high rate of return on capital in order to attract adequate capital to flow in their companies, while at the same time, they lack the evasion of market risks which will easily bring about the default risk in financing [9].

\subsection{Technical Risk and Cyber Security Risk.}

Internet finance is based on the computer technology, the network technology, and the information technology and other technologies. The application of various technologies in the development and implementation of all kinds of financial services stands at a crucial position. Yet some technical problems may also arise, thereby bringing about the operation of Internet finance being affected in the process of applying various science and technologies. The technical risk of Internet finance is mainly reflected in security risks of the system. The technical risk of Internet finance is closely related to the fact whether the application of computer network technology is reasonable and effective or not. The current common system security risks mainly include: imperfect encryption technology and poor security of the TCP/IP protocol. It is a fact that the Internet finance business can be successfully carried out by relying on computer systems. This means if the encryption technology is not perfect during the application of the computer system, the financial information stored in the computer system will be either destroyed or stolen, and the system terminal may be attacked once the hacker or virus attacks computer system, which will cause severe damages on the Internet finance. The transmission protocol adopted now is TCP/IP protocol family which features the biggest advantage of a smooth communication of information. It, however, has the biggest flaw that the low level of security, which means the information and the fund are vulnerable to be stolen during the transfer process of information or fund [10].

\subsection{Risk of Information Asymmetry.}

Internet finance means conducting financial transactions in the virtual world on the Internet, the transaction platform, with Internet financial institutions and customers as its main body. The customers and service providers do not need face to face communication thus generating the information asymmetry in Internet finance. For one thing, customers may hide their bad information in order to achieve their own goals while the financial institutions may not fully know the true assets and credit history of the customer when selecting the service target. All these have had an impact on financial institutions to make their reasonable decisions; for another, as customers do not know the actual operating ability and profitability of the financial institutions, they may not be able to choose the optimal institution when doing their selection and often they tend to choose the one with lower 
price. As a result, the relatively cheap Internet financial institutions with comparatively poor quality are more easily accepted by customers, while the Internet financial service providers with high-quality have been squeezed out of the Internet finance market due to their high prices[1].

In summary, there are currently three aspects of risk factors in Internet finance: the credit risk and the liquidity risk borne by the financial industry itself; the operational risk, the technical risk, the cyber security risk and the information asymmetry risk arising from its combination of the Internet; The regulatory risk and the market risk bringing to the government due to the rapid development of Internet finance and the variety of this emerging industry.

\section{Measures and Countermeasures for Internet Financial Risk Management}

This paper proposes the following countermeasures for the above risk factors:

\subsection{Accelerate the Process Legislative Process of Internet Financial and Improve Laws and Regulations Concerning Internet Finance.}

The complete laws and regulations are the most effective means to ensure the healthy development of Internet finance. The existing laws and regulations are not fully applicable to the industry of Internet finance for the former one cannot catch up with the booming development of the latter one. Therefore, China needs to improve related laws and regulations concerning about Internet finance based on the true reality of its Internet finance, and strengthen the supervision of Internet finance with the backing of the law. At first, the country must establish the nature and legal status of Internet finance in its legal forms, standardize the behaviors of Internet financial industry institutions, and establish a legal system that includes institutional forms, legal status, business types and scope, qualification conditions, and legal responsibilities. Second, China should complement and improve the existing traditional financial-related laws (such as commercial bank law, securities law, bank management supervision law, etc.), and add regulatory instruments adapted to the industry of Internet finance. Finally, China should establish a fair trading platform for Internet finance as soon as possible, provide complete, uniform and fair trading rules, specify the responsibilities of the transaction subjects, protect private information of consumers, thus ensuring that participants of Internet finance can have laws and rules to follow.

\subsection{Update Internet Financial Supervision Means.}

Both financial institutions and customers currently rely on real authentication and credit verification as a way to ensure a safe transaction. Therefore, China should establish an online credit bank for Internet finance companies and all the participants, build a credit management mechanism to record the basic information and credit record of financial companies, and identity information of financial participants and past transaction credit records. China should rate all companies and participants, and also update these ratings in a timely and effective manner to ensure that both companies and participants can learn the latest and the most accurate credit information in the credit bank in accordance with the standards stipulated by law. The national public security departments should strengthen the construction and investment in discovering and cracking down on crimes concerning about Internet finance, and recruit talents of scientific and technological competence equipped with Internet financial crime detection technology so that they can promptly discover suspected fraudulent enterprises and take effective measures.

\subsection{Strengthen the Supervision and Cooperation of Internet Finance and Build A Unified Internet Financial Supervision Platform.}

The existing financial regulatory agencies of China, such as the People's Bank of China, the China Banking Regulatory Commission, the China Insurance Regulatory Commission, the China Securities Regulatory Commission, etc., are just performing its own duties. Yet, there is a comprehensive regulatory body that is responsible for overseeing the emerging Internet finance industry, which may result in legally regulatory gaps. To address this issue, China needs to establish a regulatory body for Internet finance. The existing regulatory agencies can establish the specialized Internet financial regulatory departments and pool corresponding managerial personnel. Establish joint regulatory agencies with the China Banking Regulatory Commission, the China Insurance Regulatory 
Commission and the China Securities Regulatory Commission and public security agencies to provide effective regulatory measures. In addition, against the backdrop of globalization, the Internet finance has continued to develop rapidly in other developed countries with its deeper integration into the world. It hints that China can cooperate with the regulatory agencies of other countries and learn from other countries' experience and measures for Internet financial management. China can understand problems encountered in other countries as a way to prevent them in advance.

\subsection{Promote Self-Regulation of The Internet Finance Industry.}

The Internet, as burgeoning industry, has developed so rapid with fast changes that it has not yet formed a fixed pattern. The government agencies have lagged behind in the collection of information, the building of legal systems, and the implementation of supervision; hence it is often not enough to hinge on the government authority for legal supervision. What is also needed is self-discipline management in the industry. The industrial self-discipline management holds the advantage of a more comprehensive understanding about the relevant information and dynamics as the industry organization itself is in the Internet finance though this kind of regulation cannot fundamentally replace the government's official regulatory agency. Therefore, China can encourage the establishment of more Internet industry associations for more industry to industry exchanges, making the full display of the self-regulatory functions of those industry associations safeguarding the benign competition and common interests of the industry of Internet finance. And China needs to introduce the self-regulatory regulations as soon as possible, so that the industry associations have authoritative reference standards for regulation.

\subsection{Encourage Cooperation and Supervision Among Internet Finance Companies.}

Since the government and industry associations often focus on the management and the supervision of the entire industry, it may not be able to achieve a meticulous supervision for such a massive industry. Therefore, governments and industry associations can encourage and support cooperation and supervision among individual Internet finance companies. If companies in an industry can cooperate in the win-win and benign competition manner, they will be able to promote the rapid and healthy development of the industry. This will be beneficial for both consumers and companies in the industry. That is to say, Internet finance companies can send their employees to other companies to learn from and communicate with each other and understand their counterpart's management experience. It can also achieve mutual supervision. If an enterprise or employee discovers that another company has fraudulent means such as fraud, it can report it to the relevant government supervisory agency or industry association and guide the supervisor to investigate. If it is true, the regulatory agency shall punish the reported enterprise according to law and reward the relevant reporting company or individual.

\subsection{Build an Internet Finance Security System and Improve Cyber Technology Security.}

The Internet itself combined by Internet finance has huge security holes. It is evidenced by the fact that network may be attacked by viruses and hackers, thus stealing information stored on the network by the user, usurping the wealth of users and causing huge losses to them. The security of network technology is very important for the healthy and sustainable development of Internet finance. However, financial institutions often lack expertise in the research and development of the network technology. Therefore, the government should encourage and combine both scientific and technological enterprises with financial companies to work together to establish a stable and secure database. By increasing capital investment their efforts can be paid off as proved by improved the ability of hardware devices to prevent hackers and viruses. In addition, because it is likely that the network is attacked by virus or hacking from abroad, companies can work with foreign Internet finance companies to build partnership to learn how the foreign companies built their network security system and then they can apply these approaches to their own companies. At the same time, it is necessary to increase the protection of private information stored by users, and vigorously develop Internet encryption technologies, key management technologies to ensure that the private information of users will not be leaked. 


\subsection{Improve Consumer Protection.}

The great convenience brought by Internet finance has motivated more and more consumers to participate in it. However, not all participants have learned professional knowledge in finance. In other words, they cannot recognize and effectively avoid risks in Internet finance. Therefore, the government needs to improve the protection of consumers involved in Internet finance. The government should first enact relevant laws and regulations concerning consumer protection, make clear provisions on information disclosure and responsibilities of institutions during the transaction process, so that participants can conduct business acceptance in accordance with a unified process and facilitate the management of regulatory agencies. Secondly, a special consumer inquiry platform can be established to provide channels for consumers and supervisors to consult and exchange information, learn knowledge to effectively avoid risks, understand the characteristics of Internet finance operations, and product characteristics, so that consumers can clearly understand their own needs and choose the right financial product. In addition, government agencies can set up online and offline knowledge educational activities about Internet finance security by jointly cooperating with staffs in financial industry. Through these activities, the publicity and popularization of Internet finance risks and counter-risk knowledge are deepened among ordinary people.

\subsection{Enhance Efforts to Train Internet Financial Managerial Personnel and Employees.}

The managerial personnel are the regulators of the daily operation of Internet finance. The professional capabilities and qualities of these managers play a non-negligible role in the normal operation of Internet finance. Therefore, government agencies need to enhance the training of professional talents for Internet financial management. First of all, the country must strengthen the education of professional financial knowledge for financial management personnel, as well as the training of practical operational capabilities. Outstanding personnel can be sent abroad for learning and exchanges, so that they can learn about excellent and advanced management experience at home and abroad and better themselves in professional management capability. What is more, it is also necessary to strengthen the quality education of personnel, improve their professional quality to ensure that they should enforce the law impartially, and do not engage in malpractice.

The employees in Internet finance companies are also crucial for the development of a company and even the entire industry of Internet finance. The excellent Internet finance companies need the same professional financial and marketing talents as traditional financial companies. Because the talents can design innovative financial products and then sell them to many consumers after putting them into the market. In addition, the professional talents specialized in the field of computers and risk management are also needed in Internet finance companies. If the enterprise itself boasts talents in this field, it can be more convenient for it to establish and manage its own network security systems. Also, the Internet finance companies can send their employees to companies at home and abroad with advanced technology to train them on relevant professional capabilities, thus ensuring a more complete talent pool.

\subsection{Improve the Assessment System.}

Both the morale and motivation of managerial staff in regulatory agencies or staff in financial companies have tremendous impact on the development of this industry. It indicates that the assessment and the evaluation system of staff should be improved; the real-time comprehensive assessment of the initiative and effectiveness of staff in the construction of the financial system should also be conducted; a quantitative assessment should be used in the overall work performance of staffs. In addition, a reward and punishment mechanism should be adopted, so that the staff can be stimulated to be more active to complete their work tasks with high quality. On top of that, an enabling complete business and supervision services should be offered for all financial participants. By doing so, it can propel the industry to grow on the right track.

To sum up, the government should improve the laws and regulations related to Internet finance, update the Internet financial supervision methods, and strengthen the supervision and cooperation of Internet finance and international cooperation as responding measures for the existing risk factors. Apart from the legal supervision, the Internet finance industry should also be encouraged to conduct self-discipline management. Enterprises should cooperate and supervise each other, and at the same 
time, build an Internet finance security system to improve network technology security; an Internet financial credit management mechanism should be established and the consumer protection of Internet finance should also be improved. Meanwhile, the knowledge related to Internet financial security should also be publicized to the people. The regulatory agencies and the Internet finance industry must also improve the assessment and evaluation system, and increase the training of Internet finance managers and employees.

\section{Conclusion}

The rocket development of Internet finance propelled by booming Internet technology has spawned emerging financial models such as third-party payment, P2P, and crowd-funding. With bringing much convenience to people, Internet finance has gradually become an indispensable part of people's daily lives. This paper integrates the main risk factors related to Internet finance in the existing literature, and puts forward a corresponding and complete management and control strategy for the Internet finance industry. The limitation of this paper is that it does not propose independent and in-depth management measures for the existing various types of Internet finance models. What's more, it does not, in advance, make estimations of potential risk factors in the future because the Internet finance as an emerging industry is still developing and improving itself and its model is also still being innovated, and additionally some new financial risks may emerge in the future.

\section{References}

[1]. Xu Key. Risk Management and Countermeasures of China's Internet Finance [J]. Journal of Chafing University (Natural Science Edition). 2015. 03.

[2]. Yang Xiaowei, Wei Jiu, Fang Hangout. Research on Risk Management of Internet Finance [J]. Modern Management Science. 2016. No.4.

[3]. Fu Hangman. Research on the Characteristics of Internet Financial Risk and Its Prevention and Control Strategies [J]. Hainan Finance. 2016.

[4]. Yang Guiyang. Research on Countermeasures of Internet Financial Risk Prevention [J]. Modern Economic Information. 2015. 09.

[5]. Shen Li, Lin Dingdong. Literature Review of Internet Financial Risk Management [J]. Journal of Shandong University of Finance and Economics. 2014. 09.

[6]. Chen Xiaorui. Internet financial risk management and prevention strategies. Shingling [J]. Account Analysis. 2017. No.28.

[7]. Li Wei. A Survey of Research on Internet Financial Risk and Prevention [J]. Review of Economic Research. 2017. No.54.

[8]. Zhang Song, Shi Jingle, Lei Ding. Research on Operational Risk Management under Internet Finance [J]. New Finance. 2013. 09.

[9]. Zhang Zhuomei. Analysis of Internet Financial Risk Management [J]. Finance Economy. 2017. 06.

[10]. Xing Huainan, Liu Jianqiao. Internet Financial Risk and Risk Prevention Research [J]. China Business \& Trade. 2014. 12.

[11]. Xu Ming. Research on Internet Financial Risk and Risk Management [J]. China Business \& Trade. 2017. 01. 